\title{
Reduced sediment transport in the Yellow River due to anthropogenic changes
}

\author{
Shuai Wang ${ }^{1,2}$, Bojie Fu' ${ }^{1,2 \star}$, Shilong Piao ${ }^{3,4}$, Yihe Lü ${ }^{1,2}$, Philippe Ciais ${ }^{5}$, Xiaoming Feng ${ }^{1,2}$ \\ and Yafeng Wang ${ }^{1,2}$
}

The erosion, transport and redeposition of sediments shape the Earth's surface, and affect the structure and function of ecosystems and society ${ }^{1,2}$. The Yellow River was once the world's largest carrier of fluvial sediment, but its sediment load has decreased by approximately $90 \%$ over the past 60 years $^{3}$. The decline in sediment load is due to changes in water discharge and sediment concentration, which are both influenced by regional climate change and human activities. Here we use an attribution approach to analyse 60 years of runoff and sediment load observations from the traverse of the Yellow River over China's Loess Plateau - the source of nearly $90 \%$ of its sediment load. We find that landscape engineering, terracing and the construction of check dams and reservoirs were the primary factors driving reduction in sediment load from the 1970s to 1990s, but large-scale vegetation restoration projects have also reduced soil erosion from the 1990s onwards. We suggest that, as the ability of existing dams and reservoirs to trap sediments declines in the future, erosion rates on the Loess Plateau will increasingly control the Yellow River's sediment load.

Change of soil erosion and the resulting river sediment transport are important components of global change, so understanding the mechanisms behind such change is crucial to developing strategic plans for the sustainable management of catchments ${ }^{4,5}$. In recent decades, significant decreasing trends in river sediment loads have been observed in approximately $50 \%$ of the world's rivers ${ }^{6,7}$. The benefits and risks of the change in river sediment load largely depend on the baseline load and the scale of the change $e^{8,9}$. Hence, it is important to quantify the change of river sediment loads through time, and to understand the drivers and mechanisms behind them ${ }^{2,5}$.

The Huang He, or Yellow River (YR) (Fig. 1), was the most sediment-laden river in the world, but its annual sediment load has continually decreased since the 1950s (refs 10-13). The yearly sediment loads at the main gauging stations along the YR, all show significant decreasing trends $(p<0.01)$ over the past six decades (Fig. 1b). Sediment load increases most suddenly in the middle reach of the river, when crossing the Loess Plateau (LP), between the Toudaoguai gauging station (TDG) $\left(0.07 \mathrm{Gt} \mathrm{yr}^{-1}\right)$ and the Tongguan station (TG) $\left(0.63 \mathrm{Gt} \mathrm{yr}^{-1}\right)$, and then gradually declines in the lower reach (Fig. 1b, top right inset). The LP is thus the largest sediment source, nearly $90 \%$ (refs 3,11) for the YR, and we therefore focus on this part of the river's catchment. A mass budget over the middle reach of the YR can be obtained from the difference of measured sediment flux and water discharge at TG and TDG (Fig. 1). Both the river discharge and sediment load across the
LP show significant decreasing trends $\left(-0.25 \mathrm{~km}^{3} \mathrm{yr}^{-2}, p<0.001\right.$; and $-0.02 \mathrm{Gt} \mathrm{yr}^{-2}, p<0.001$, respectively) over the past six decades, whereas precipitation decreased slightly $\left(-1.2 \mathrm{~mm} \mathrm{yr}^{-2}, p=0.015\right)$. As Fig. 2a shows two abrupt falls in sediment load around the years 1979 and 1999, we thus divided the past 60 years into three periods covering 1951-1979 (P1), 1980-1999 (P2), and 2000-2010 (P3). Figure $2 \mathrm{~b}$ shows a pronounced decrease of sediment load, from $1.34 \pm 0.64 \mathrm{Gt} \mathrm{yr}^{-1}$ during P1 to $0.73 \pm 0.28 \mathrm{Gt} \mathrm{yr}^{-1}$ during P2, and

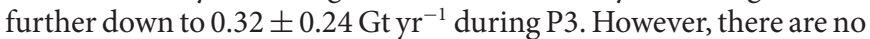
obvious discontinuities in the double mass plots of annual sediment load versus water discharge (Supplementary Fig. 1).

We calculated the Sediment Identity with the observed trends of regional average precipitation $(P)$, water yield capacity $(r)$ and sediment concentrations $(s)$ over 1951-2010 (Supplementary Figs 2 and 3). During the past six decades, the relative rate of change of sediment load $S$ across the LP was $-2.38 \% \mathrm{yr}^{-1}$, with $12 \%$ of this decrease being the result of decreasing $P, 58 \%$ by a coincident reduction of $r$, and the remaining $30 \%$ being attributable to reduced $s$ (Supplementary Table 1 and Fig. 3a). Specifically, for P1 and P2, $r$ has the largest negative proportional change rate of $-1.26 \% \mathrm{yr}^{-1}$, this driver accounting alone for $83 \%$ of the overall reduction in $S$, with decreased $P$ contributing $22 \%$. Changes in sediment concentration, $s$, increased at a rate of $0.08 \% \mathrm{yr}^{-1}$ during P1 and P2, and contributed a small increase of $5 \%$ to the relative trend of $S$. The relative reduction of $S$ between P2 and $\mathrm{P} 3$, equivalent to a mean decrease of $-4.49 \% \mathrm{yr}^{-1}$, mostly resulted from a coincident decrease of $r\left(-3.15 \% \mathrm{yr}^{-1}\right)$ and $s\left(-1.17 \% \mathrm{yr}^{-1}\right)$, whereas decreasing precipitation only contributed to approximately $4 \%$ of the relative reduction in $S$. Among the 12 main tributary catchments (Supplementary Table 2), the largest contribution to the YR sediment load reduction seems to come from the Kuye (Fig. 1) (Supplementary Figs 4 and 5). Especially during P2 and P3, the relative rate of change of $S$ was $-7.45 \% \mathrm{yr}^{-1}$, a large decrease attributed mainly to the reduction of $s(56 \%)$ and $r(46 \%)$, whereas precipitation changes made a very small negative contribution $(-2 \%)$. The Jinghe makes the largest sediment contribution to the YR in the LP (increases from $17 \%$ during P1 to $29 \%$ during P2 and more than $40 \%$ during $\mathrm{P} 3$ ), and with the lowest relative rate of change of sediment load $\left(-0.94 \% \mathrm{yr}^{-1}\right)$, but contributed more than $10 \%$ of the reduced sediment for the YR during P1 and P3 (Supplementary Fig. 5).

These results highlight the dominant role of decreased water yield capacity $(r)$ in controlling the observed sediment load reduction. The raw sediment concentration data of TG and TDG gauging stations suggest that the YR really did become cleaner during

\footnotetext{
${ }^{1}$ State Key Laboratory of Urban and Regional Ecology, Research Center for Eco-Environmental Sciences, Chinese Academy of Sciences, Beijing 100085, China. ${ }^{2}$ Joint Center for Global Change Studies, Beijing 100875, China. ${ }^{3}$ College of Urban and Environmental Sciences, Peking University, Beijing 100871 , China. ${ }^{4}$ Laboratory of Alpine Ecology and Biodiversity, Institute of Tibetan Plateau Research, Chinese Academy of Sciences, Beijing 100101, China. ${ }^{5}$ Laboratoire des Sciences du Climat et de I'Environnement, CEA CNRS UVSQ, 91191 Gif-sur-Yvette, France. *e-mail: bfu@rcees.ac.cn
} 

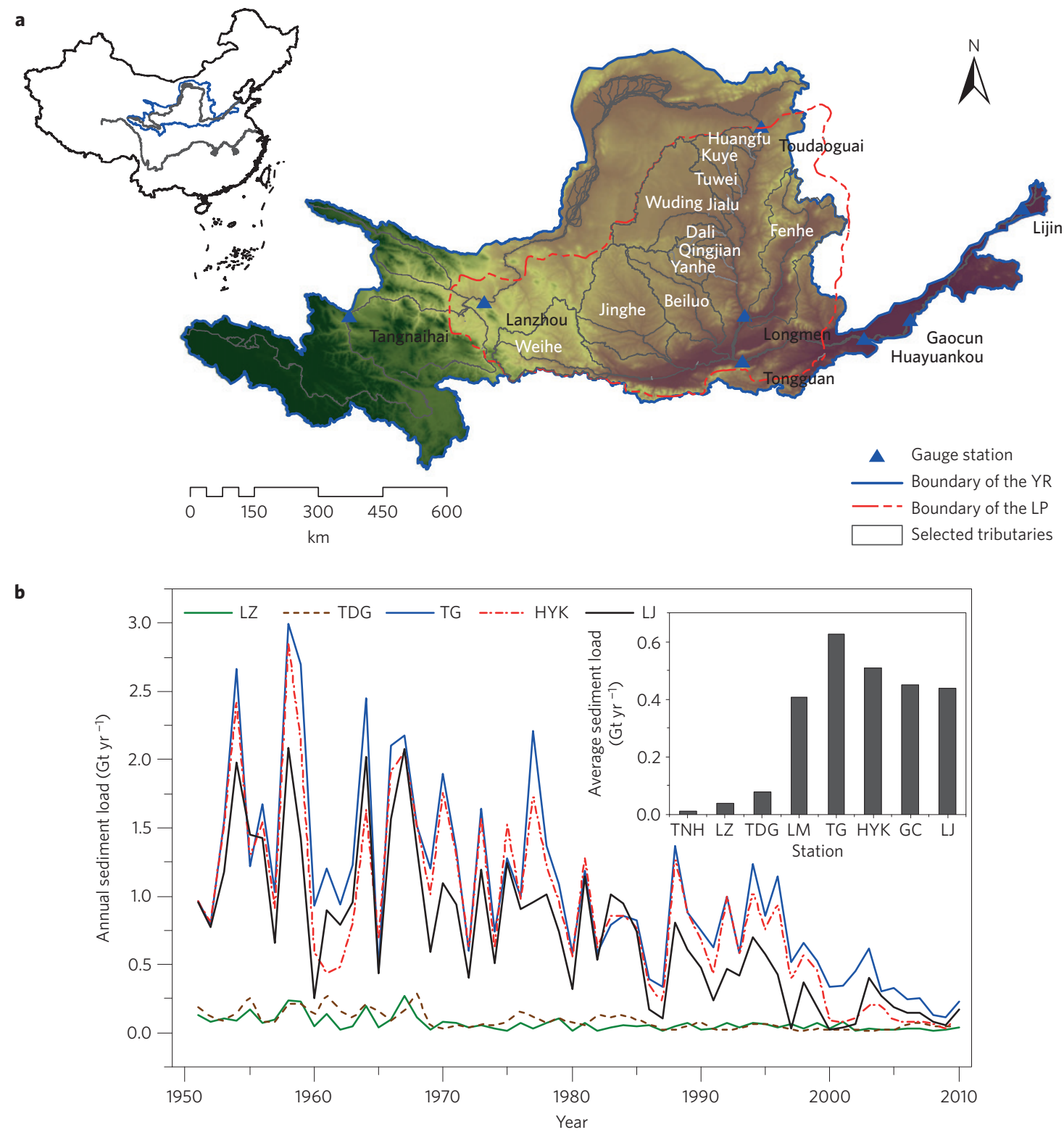

Figure 1 | Location of the Loess Plateau (LP) and the Yellow River (YR) basin and the hydrologic regime of the YR in recent decades. a, Selected tributaries and gauging stations along the main stream. $\mathbf{b}$, The time series of yearly sediment load at the main gauging stations along the YR. Inset: the average annual sediment load from 1951 to 2010 at gauging stations along the mainstream of the YR. TNH, Tangnaihai; LZ, Lanzhou; TDG, Toudaoguai; LM, Longmen; TG, Tongguan; HYK, Huayuankou; GC, Gaocun; LJ, Lijin.

these decades. The average annual air temperature in the LP also has significantly increased over the past 60 years $\left(0.22^{\circ} \mathrm{C}\right.$ per decade, $p<0.01$ ) (Supplementary Fig. 3). The evapotranspiration coefficient $(\mathrm{E} / \mathrm{P})$ of the main tributaries progressively increased as time progressed between $\mathrm{P} 1$ and $\mathrm{P} 3$, implying that the surface conditions have been significantly modified ${ }^{14,15}$, especially during P2 and P3 (Supplementary Fig. 6). Afforestation, terraced farming, and the construction of check dams and reservoirs are the major human interventions in this area that have led to increased precipitation retention (Supplementary Table 3), and the consequent reduction of river sediment flux ${ }^{3,10-12,16}$.

One of the most effective methods of stabilizing soils and minimizing erosion is to establish perennial vegetation cover ${ }^{13,17,18}$. Such vegetation cover in the LP has significantly increased as a result of some large-scale vegetation rehabilitation programmes, particular the 'Grain-for-Green' programme (GFGP) launched in 1999 (refs 19,20). Remote sensing data indicate that the average vegetation coverage of the 12 main YR sub-catchments on the LP increased from $25 \%$ in 1978 , to $29 \%$ in 1998 , and then to $46 \%$ in 2010 (Supplementary Fig. 7a). Linear regressions suggest that, comparing $\mathrm{P} 1$ to $\mathrm{P} 2$, a decrease of $4 \%$ in water yield and $3 \%$ in sediment concentration can be attributed to vegetation restoration. Between P2 and P3, when massive afforestation took place, these figures increased to $26 \%$ and $21 \%$, respectively (Supplementary Fig. $7 \mathrm{~b}, \mathrm{c})$. About $10 \%\left(0.06 \mathrm{Gt} \mathrm{yr}^{-1}\right)$ of the reduction in average sediment transport between P1 and P2 and 57\% (0.23 $\left.\mathrm{Gtyr}^{-1}\right)$ between $\mathrm{P} 2$ and $\mathrm{P} 3$ resulted from the increased vegetation coverage (Methods).

Terrace farming is a long accepted method of reducing sediment flux into river systems $s^{5,21}$. In the catchments of the 12 tributaries, the average area under terrace farming has increased from $2 \%$ in 1979 to $7 \%$ in 1999, and then to 9\% in 2006 (Supplementary Fig. 8a). Using a method proposed by Liu et al. ${ }^{21}$, we estimated that terrace construction contributed to the reduced sediment load by $0.21 \mathrm{Gt} \mathrm{yr}^{-1}$ 
a

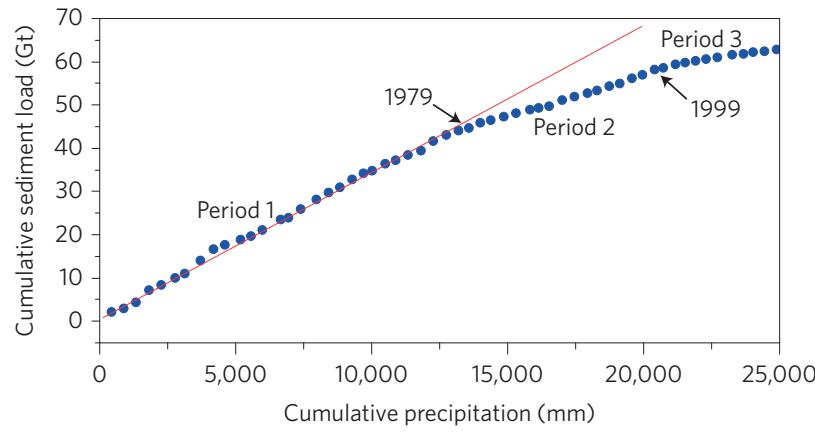

b

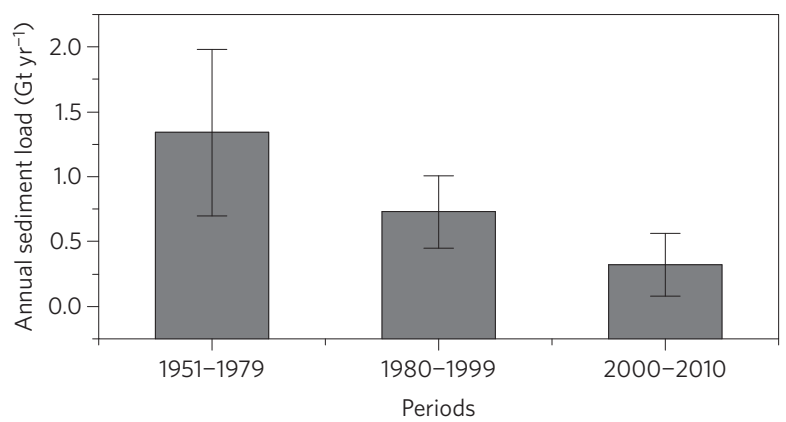

Figure 2 | Decreases in the sediment load of the YR from the LP during recent decades. a, Relationship between cumulative sediment load in the LP reach of the YR (the difference between TG and TDG stations) and cumulative precipitation on the LP. $\mathbf{b}$, Average annual sediment load in the $L P$ reach of the $Y R$ over three periods, error bars are the standard deviation across the years. The annual load shows a significant reduction during these periods.

between P1 and P2, and $0.07 \mathrm{Gt} \mathrm{yr}^{-1}$ between P2 and P3 (33 and 17\% of the total reduction, respectively; Supplementary Fig. 8b)

Check dams are another effective measure to reduce sediment load in rivers and have the co-benefit of creating fertile flat agricultural land ${ }^{22}$. A national census suggests that there are 5,340 key dams (storage capacity $>50 \times 10^{4} \mathrm{~m}^{3}$ ) in the tributaries feeding the middle reaches of the YR, and sediment has filled 1,090 of these dams. There are also more than 50,000 moderate and small dams (storage capacity $<50 \times 10^{4} \mathrm{~m}^{3}$ ) in this region, of which approximately 6,300 are still functional in sediment retention. The same national census also reports that there are at present more than 960 reservoirs on the LP. The effectiveness of check dams and reservoirs decreases with time as they progressively fill with eroded

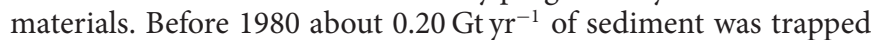
behind dams and in reservoirs. Trapped sediment flux reached its maximum value of $0.33 \mathrm{Gt} \mathrm{yr}^{-1}$ in the 1990s (Methods). However, in recent years it has gradually reduced to $0.29 \mathrm{Gt} \mathrm{yr}^{-1}$ (Supplementary Fig. 8c). Thus, check dams and reservoirs seem to account for $21 \%$ of the total reduction between period $\mathrm{P} 1$ and period $\mathrm{P} 2$, but $-9 \%$ between P2 and P3, as their storage capacity became saturated.

In total, the increase in perennial vegetation coverage, terrace farming, construction of check dams and reservoirs account for $64 \%$ of the sediment load reduction across the LP during P1 and P2, and for $65 \%$ of the reduction during P2 and P3 (Fig. 3b). The other effects contributing to the rest of the observed sediment reduction can be related to uncertainties, non-additive terms and interactions between activities, and to factors such as the increase in human water consumption, sand extraction and regional climate change $e^{23}$. On the LP, human water consumption has increased by $86 \%$ from the 1980 s to 2010, according to the Yellow River Water Resources Bulletin. From 2000 to 2010 , in particular, it increased from $1.04 \mathrm{~km}^{3} \mathrm{yr}^{-1}$ to $1.59 \mathrm{~km}^{3} \mathrm{yr}^{-1}$ (Methods). This increase in human water consumption will reduce the water yield, which in turn reduces $S$.
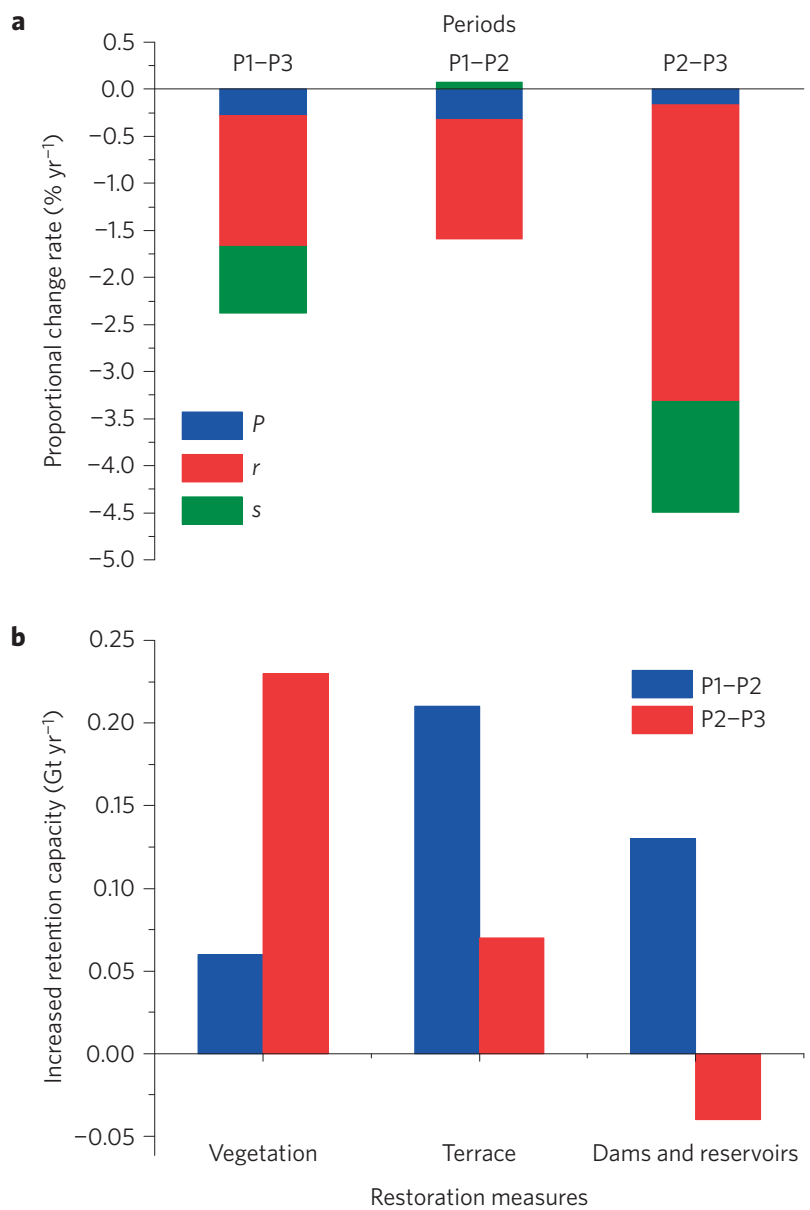

Figure 3 | The proportional decrease rate of the sediment flux $(S)$ and its drivers. a, Contributions of the Sediment Identity factors between the periods $\mathrm{P} 1$ and $\mathrm{P} 3, \mathrm{P} 1$ and $\mathrm{P} 2$, and $\mathrm{P} 2$ and $\mathrm{P} 3$, including the contributions of precipitation $(P)$, water yield capacity $(r)$ and sediment concentration (s) that summed together give the change in sediment load $(S)$.

b. Contributions of specific restoration measures towards sediment reduction.

Throughout the entire history of China, diverse strategies and techniques have been applied to attempt to control the sediment transport of the YR (refs 3,12,24). Most of these measures were focused on the river channel: trapping sediment or diverting floods ${ }^{13,16}$. But now, through the combined effects of many dams and afforestation (which both reduce source erosion and runoff transport of eroded material), the sediment load has been regulated to a near pre-human level-that is, that before around AD 600 (refs 2,25). This change has been achieved: by adding civil engineering structures to slow down river flow and capture the sediment; by agricultural engineering, through introducing largescale terraced farming; and finally by what we might call 'ecosystem engineering', large-scale land use change with the replacement of arable agriculture by plantations of perennial vegetation.

To replace the slowly filling sediment trapping systems, vegetation restoration must in future play a bigger role in soil and water conservation for the LP (Supplementary Fig. 9). How to maintain a sustainable vegetated ecosystem is now the key question. Vegetation plantations, especially tree plantations, in this arid and semiarid area have a high water demand ${ }^{20,26}$. Extensive forest plantations intercept rainfall before it can reach the soil, and the deep roots can extract underground water and reduce soil moisturesoil protection may thus come at the cost of greater water use $\mathrm{e}^{27}$. A careful evaluation of the headwater catchment ecosystems based on 
water-climate-vegetation interactions, and selection of appropriate species and locations, is thus extremely important in designing sustainable ecosystems for this fragile loess-soil-dominated land ${ }^{20}$.

Even if the data presented here show that the massive sediment input to the YR can be effectively managed down to return almost to pre-human levels, a full sustainability analysis of the impacts of reduced sediment load on the lower reach of the river and its estuary remains to be done. The reduced sediment supply to the lower reach and estuary has already shifted the YR delta to an erosional phase ${ }^{28}$, potentially affecting more than two million people ${ }^{29}$. Further, as a majority of climate models are projecting an increase of precipitation over the YR catchment, whereas the capacity of soil conservation and engineering measures to capture sediment will inevitably saturate over time, we must also pay attention to preventing a river sediment load rebound.

\section{Methods}

Methods and any associated references are available in the online version of the paper.

Received 7 September 2015; accepted 22 October 2015; published online 30 November 2015

\section{References}

1. Syvitski, J. P. M. Supply and flux of sediment along hydrological pathways: Research for the 21st century. Glob. Planet. Change 39, 1-11 (2003).

2. Walling, D. E. The Impact of Global Change on Erosion and Sediment Transport by Rivers: Current Progress and Future Challenges (UNESCO, 2009).

3. Yu, Y. et al. New discharge regime of the Huanghe (Yellow River): Causes and implications. Cont. Shelf Res. 69, 62-72 (2013).

4. Beechie, T. J. et al. Process-based principles for restoring river ecosystems. Bioscience 60, 209-222 (2010)

5. Syvitski, J. P. M. \& Kettner, A. Sediment flux and the Anthropocene. Phil. Trans. R. Soc. A 369, 957-975 (2011).

6. Walling, D. E. \& Fang, D. Recent trends in the suspended sediment loads of the world's rivers. Glob. Planet. Change 39, 111-126 (2003).

7. Syvitski, J. P. M., Vörösmarty, C. J., Kettner, A. J. \& Green, P. Impact of humans on the flux of terrestrial sediment to the global coastal ocean. Science 308, 376-380 (2005).

8. Montgomery, D. R. Soil erosion and agricultural sustainability. Proc. Natl Acad. Sci. USA 104, 13268-13272 (2007).

9. Giosan, L., Syvitski, J., Constantinescu, S. \& Day, J. Climate change: Protect the world's deltas. Nature 516, 31-33 (2014).

10. Wang, H. J. et al. Stepwise decreases of the Huanghe (Yellow River) sediment load (1950-2005): Impacts of climate change and human activities. Glob. Planet. Change 57, 331-354 (2007).

11. Wang, H. J. et al. Recent changes in sediment delivery by the Huanghe (Yellow River) to the sea: Causes and environmental implications in its estuary. J. Hydrol. 391, 302-313 (2010).

12. Xu, J. X. Effect of human activities on overall trend of sedimentation in the lower Yellow River, China. Environ. Manage. 33, 637-653 (2004).

13. Fu, B. J. Soil erosion and its control in the Loess Plateau of China. Soil Use Manage. 5, 76-82 (1989).

14. Wang, D. \& Hejazi, M. Quantifying the relative contribution of the climate and direct human impacts on mean annual streamflow in the contiguous United States. Water Resour. Res. 47, W00J12 (2011).
15. Liang, W. et al. Quantifying the impacts of climate change and ecological restoration on streamflow changes based on a Budyko hydrological model in China's Loess Plateau. Water Resour. Res. 51, 6500-6519 (2015).

16. Miao, C. Y., Ni, J. R. \& Borthwick, A. G. L. Recent changes in water discharge and sediment load of the Yellow River basin, China. Prog. Phys. Geogr. 34, 541-561 (2010)

17. Liu, X. Y. et al. Response of sediment yield to vegetation restoration at a large spatial scale in the Loess Plateau. Sci. China Tech. Sci. 57, 1482-1489 (2014).

18. Liu, X. Y. et al. Influences of shrubs-herbs-arbor vegetation coverage on the runoff based on the remote sensing data in Loess Plateau. Acta Geogr. Sin. 69 1595-1603 (2014).

19. Feng, X. M., Fu, B. J., Lu, N., Zeng, Y. \& Wu, B. F. How ecological restoration alters ecosystem services: An analysis of carbon sequestration in China's Loess Plateau. Sci. Rep. 3, 2846 (2013).

20. Chen, Y. et al. Balancing green and grain trade. Nature Geosci. 8 , 739-741 (2015)

21. Liu, X. Y. et al. Analysis on sediment yield reduced by current terrace and shrubs-herbs-arbor vegetation in the Loess Plateau. J. Hydraul. Eng. 45, 1293-1300 (2014).

22. Wang, Y. F., Fu, B. J., Chen, L. D., Lü, Y. H. \& Gao, Y. Check dam in the Loess Plateau of China: Engineering for environmental services and food security. Environ. Sci. Technol. 45, 10298-10299 (2011).

23. Wang, Q. X., Fan, X. H., Qin, Z. D. \& Wang, M. B. Change trends of temperature and precipitation in the Loess Plateau Region of China, 1961-2010. Glob. Planet. Change 92-93, 138-147 (2012).

24. Fu, B. J. et al. Assessing the soil erosion control service of ecosystems change in the Loess Plateau of China. Ecol. Complexity 8, 284-293 (2011).

25. Shi, C., Dian, Z. \& You, L. Changes in sediment yield of the Yellow River basin of China during the Holocene. Geomorphology 46, 267-289 (2002).

26. Wang, S. et al. Soil moisture and evapotranspiration of different land cover types in the Loess Plateau, China. Hydrol. Earth Syst. Sci. 16, 2883-2892 (2012).

27. Jackson, R. B. et al. Trading water for carbon with biological sequestration. Science 310, 1944-1947 (2005)

28. Bi, N., Wang, H. \& Yang, Z. Recent changes in the erosion-accretion patterns of the active Huanghe (Yellow River) delta lobe caused by human activities. Cont. Shelf Res. 90, 70-78 (2014).

29. Zhou, Y., Huang, H. Q., Nanson, G. C., Huang, C. \& Liu, G. Progradation of the Yellow (Huanghe) River delta in response to the implementation of a basin-scale water regulation program. Geomorphology 243, 65-74 (2015).

\section{Acknowledgements}

This work was funded by the National Natural Science Foundation of China (No. 41390464, 41401027) and the Chinese Academy of Sciences (No. GJHZ 1502). We thank J. Gash for his assistance with the English language editing.

\section{Author contributions}

B.F., S.W. and S.P. designed the research. S.W., S.P. and P.C. performed the Sediment Identity analysis. Y.L. and S.W. performed trend analysis. S.W. and X.F. performed vegetation effects analysis. S.W. and Y.W. analysed the effects of engineering measures. All authors contributed to the interpretation and writing.

\section{Additional information}

Supplementary information is available in the online version of the paper. Reprints and permissions information is available online at www.nature.com/reprints.

Correspondence and requests for materials should be addressed to B.F.

\section{Competing financial interests}

The authors declare no competing financial interests. 


\section{Methods}

Data. Yearly runoff and sediment load data from the main gauging stations along the YR and 12 tributaries on the LP (1951-2010) were obtained from the Bureau of Hydrology, Yellow River Conservancy Commission (YRCC) and collected from Yellow River Water Resources Bulletin (http://www.yellowriver.gov.cn/ nishagonggao). Meteorological data from 1951-2010 were provided by the National Meteorological Administration of China (http://data.cma.cn). Records of soil and water conservation measures, including terraces, dams and reservoirs were provided by YRCC, the Yellow River Water Conservancy Yearbook, and the Bulletin of the First National Water Resource Census. Water consumption data were also obtained from Yellow River Water Resources Bulletin (http://www.yellowriver.gov.cn/nishagonggao). Vegetation coverage, including information on forest and grassland area, was extracted and calculated with remote sensing images from the summer or autumn of 1978 (Landsat MSS), 1998 (Landsat TM) and 2010 (HJ CCD), at spatial resolutions of $56 \mathrm{~m}, 30 \mathrm{~m}$ and $30 \mathrm{~m}$, respectively. Data of tributary sub-catchment vegetation coverage, terraced area proportion, runoff coefficient, and suspended-sediment concentration were collected from published papers and used to analyse the relationship between sediment production, and water and soil conservation measures ${ }^{15,17,18,21}$.

Sediment identity factors decomposition. We develop a simple attribution approach, 'Sediment Identity' (analogous to the Kaya Identity in economics ${ }^{30,31}$ ), to diagnose the contributions of precipitation $(P)$, water yield capacity $(r$, the ratio of river discharge to precipitation) and sediment concentration ( $s$, the ratio of annual sediment mass flux to discharge) to the relative rate of change of sediment load in the YR.

The Sediment Identity combines the variables of regional average precipitation $(P)$ and water discharge $(R)$ in a causal relationship to the sediment load $(S)$-thus, finally, the $S$ can be regarded as the integration of the three variables:

$$
S=P\left(\frac{R}{P}\right)\left(\frac{S}{R}\right)=P r s
$$

We then define the proportional change rate of a quantity $X(t)$ as $r(X)=X^{-1} \mathrm{~d} X / \mathrm{d} t$. Because $((\mathrm{d} S / \mathrm{d} t) / S)=((\mathrm{d}(P r s) / \mathrm{d} t) / P r s)=((\mathrm{d} P / \mathrm{d} t) / P)$ $+((\mathrm{d} r / \mathrm{d} t) / r)+((\mathrm{d} s / \mathrm{d} t) / s)$, the counterpart of the sediment identity for proportional change rates can be rewritten as

$$
r(S)=r(P)+r(r)+r(s)
$$

Using long time series of $P, r$ and $s$ observations, we applied the above identity to diagnose the role of each driver to the observed sediment load trend. The theoretical proportional change rate, which summed factors including $P, r$ and $s$, closely approximates the rate of $S$ actually encountered.

We first decomposed the trend in sediment load, $S$, into three hydrologic factors: $P, r$ and $s$. We calculated their rates of change over the whole period, for periods $\mathrm{P} 1$ to $\mathrm{P} 2$, and for periods $\mathrm{P} 2$ to $\mathrm{P} 3$, using a linear regression method, and normalizing them by their corresponding mean values, respectively. The relative contribution of each identity factor is the ratio of its proportional change rate to the proportional change rate of $S$ during the same period. In addition, we performed statistical regression analysis of $r$ (or $s$ ) with the climate, vegetation coverage and terrace density to further investigate the dominant driving forces behind change in $r$ and $s$, as well as $S$.

Contribution assessment of specific human restoration measures. We assessed the contribution from different human interventions to the observed reduction in river sediment flux using various linear regression analyses. To calculate the contribution of vegetation coverage changes, we used the tributary catchment data of runoff coefficient, suspended-sediment concentration and vegetation coverage collected by Liu and colleagues ${ }^{17,18}$. These data focused on catchments with the least dams, reservoirs and terracing. We established a linear relationship between the vegetation coverage and runoff coefficient $\left(y=-0.048 x+4.65, R^{2}=0.72\right)$ and flow sediment concentration $\left(y=-5.94 x+657.28, R^{2}=0.74\right)$ from the above literature data (Supplementary Fig. 7), and then calculated the contribution of vegetation coverage increase to water discharge and sediment yield for 12 tributaries. We then extrapolated to the whole LP. Similarly, the sediment intercepted by terraces was estimated by fitting a linear regression between terrace density and sediment reduction rate ${ }^{21}$. We also used these relationships to make predictions under future scenarios. The sediment captured by reservoirs and check dams was estimated according to the numbers of reservoirs and dams and their trapping rates, which were then summed for the whole LP.

\section{References}

30. Kauppi, P. E. et al. Returning forests analyzed with the forest identity. Proc. Natl Acad. Sci. USA 103, 1754-1759 (2006).

31. Raupach, M. R. et al. Global and regional drivers of accelerating $\mathrm{CO}_{2}$ emissions. Proc. Natl Acad. Sci. USA 104, 10288-10293 (2007). 